\title{
Occurrence of metastatic eccrine porocarcinoma in an immunosuppressed patient
}

\author{
Mitul B. Modi ${ }^{1 *} \mathbb{D}$, Ata S. Moshiri ${ }^{2}$, Toru Shoji ${ }^{3}$, Martin C. Mihm Jr ${ }^{4}$, Xiaowei Xu ${ }^{5}$ and David E. Elder ${ }^{5}$
}

\begin{abstract}
Background: Eccrine porocarcinoma is a rare malignancy accounting for 0.005 to $0.01 \%$ of all cutaneous tumors. However, its etiology is not well established. Herein we are reporting the occurrence of metastatic porocarcinoma of the back in a patient with a history of multiple cutaneous malignancies and chronic immunosuppression.

Case presentation: A 79-year-old male with a history of long-term immunosuppressive therapy for left lung transplantation and multiple cutaneous malignancies including melanoma, presented with an enlargening plaque on the right upper back. Biopsy demonstrated an infiltrative epithelial tumor with aggressive histology and ductal formation. Immunohistochemical stains for p63, CK-5/6, and CEA were diffusely positive, while CK-7 and CK-20 were negative. A diagnosis of eccrine porocarcinoma was made. He underwent complete wide excision with negative margins of the right upper back in January 2018. In November 2018, he was found to have a right posterior shoulder mass, positive right axillary lymph nodes, superficial right upper back soft tissue masses and lymphangitic carcinomatosis involving the left lung. He was transitioned to comfort care and subsequently passed from metastatic disease in December 2018.
\end{abstract}

Conclusion: The occurrence of eccrine porocarcinoma in a patient on long term immunosuppressive therapy for lung transplantation suggests a possible role for chronic immunosuppression in the induction of a subset of eccrine porocarcinomas, as in other cutaneous malignancies.

Keywords: Eccrine porocarcinoma, Infiltrating margin, Squamous cell carcinoma, Immunosuppression, Cutaneous lesions

\section{Introduction}

Eccrine porocarcinoma (EPC), was first described in 1963 by Pinkus and Mehregan. EPC, also known as "malignant eccrine poroma," accounts for 0.005 to $0.01 \%$ of all cutaneous malignancies, although the exact prevalence is unknown.(Salih et al., 2017a) It has been proposed that the tumor developed from a pre-existing eccrine poroma and factors such as exposure to chemical agents, chronic sun exposure, and immunosuppression could be the predisposing factors for de novo EPC.(Salih et al., 2017a)

\footnotetext{
* Correspondence: mitul.modi7@gmail.com

${ }^{1}$ Department of Pathology and Laboratory Medicine, Pennsylvania Hospital of the University of Pennsylvania Health System, Philadelphia, PA, USA Full list of author information is available at the end of the article
}

Despite these conjectures, its etiology is not well established.(Salih et al., 2017b) EPC develops from the intraepidermal ductal portion of the sweat gland.(Riera-Leal et al., 2015). The peak incidence occurs around 67 years of age and the majority of the patients are usually older, but it can affect children or young adults.(Salih et al., 2017b; Riera-Leal et al., 2015) A slight predominance in women has been observed.(Salih et al., 2017b; Riera-Leal et al., 2015). The head and neck are the most common location followed by lower extremity.(Salih et al., 2017b; Riera-Leal et al., 2015). The majority of published literature are single case reports, but few case series exist; some of them reporting only histopathologic findings and few describing clinical aspects only.(Riera-Leal et al., 2015)

(c) The Author(s). 2020 Open Access This article is licensed under a Creative Commons Attribution 4.0 International License, which permits use, sharing, adaptation, distribution and reproduction in any medium or format, as long as you give appropriate credit to the original author(s) and the source, provide a link to the Creative Commons licence, and indicate if changes were made. The images or other third party material in this article are included in the article's Creative Commons licence, unless indicated otherwise in a credit line to the material. If material is not included in the article's Creative Commons licence and your intended use is not permitted by statutory regulation or exceeds the permitted use, you will need to obtain permission directly from the copyright holder. To view a copy of this licence, visit http://creativecommons.org/licenses/by/4.0/. 
Herein we are reporting a case of 79-year-old male patient with a history of iatrogenic immunosuppression who died of metastatic eccrine porocarcinoma, with a detailed review of cases and studies from the literature to date.

\section{Case presentation}

A 78 year old male on a routine follow-up visit for melanoma of his lower back in December 2017, was found to have a large, asymptomatic, scaly plaque on the right upper back. His medical history was significant for left lung transplantation for chronic obstructive pulmonary disease. Biopsy of the lesion showed an epidermal based neoplasm with anastomosing cords of tumor cells extensively infiltrating into the dermis and involving the deep margins (Figs. 1 and 2). Immunohistochemical stains for p63, cytokeratin (CK)-5/6 and carcinoembryonic antigen (CEA) (Fig. 3) were diffusely positive, whereas CK-7 and CK-20 were negative. A diagnosis of eccrine porocarcinoma was made. Excision with appropriate negative margins, sentinel lymph node biopsy and workup for possible metastasis were recommended.

The patient underwent complete wide excision of the right upper back lesion in January 2018. Preoperatively he underwent computed tomography (CT) imaging of chest, abdomen and pelvis for staging. Chest CT was unremarkable concerning metastatic disease, but $\mathrm{CT}$ abdomen and pelvis showed indeterminate hepatic lesions as well as a prominent right inguinal lymph node. Magnetic Resonance Imaging (MRI) abdomen showed benign hepatic lesions as well as a cystic nodule in the right groin. He was deemed to have no evidence of distant metastasis at that time.

In November 2018, the patient was admitted to an outside medical institution for a two-month history of an enlarging right shoulder mass that began to ooze

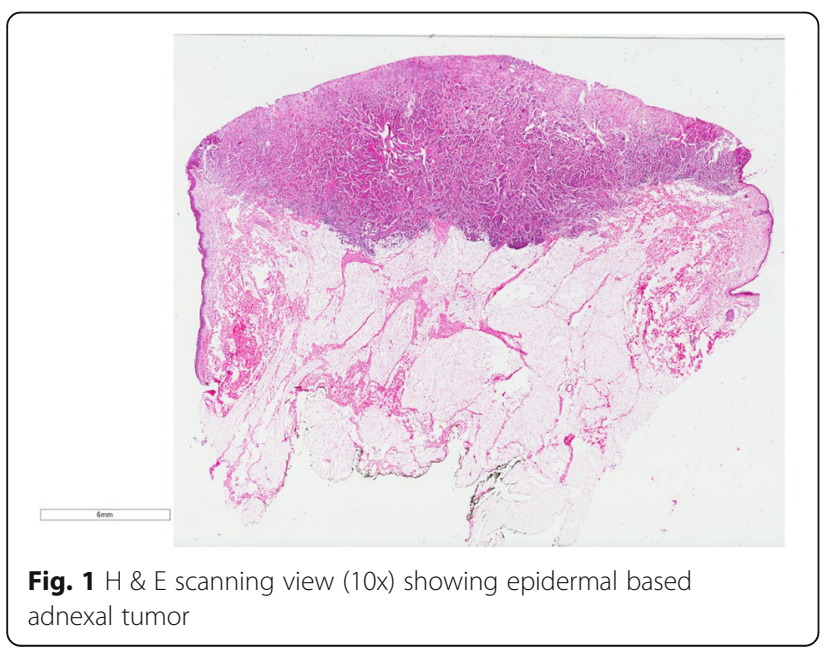

foul-smelling drainage. On review of systems, he also complained of worsening dyspnea on exertion, cough productive of dark brown/red sputum, and $10 \mathrm{lbs}$. weight loss. Given concerns for superficial skin infection, he was managed with intravenous (IV) antibiotics and transferred to our institution for further treatment. CT imaging of his neck showed a heterogeneous necrotic mass along the right upper back and shoulder (Fig. 4). Repeat chest CT was significant for likely malignant right axillary lymph nodes and superficial right upper back soft tissue masses, small left pleural effusion and lymphangitic carcinomatosis involving the left lung predominantly. The biopsy of the shoulder mass showed recurrent eccrine porocarcinoma (Figs. 5 and 6).

The patient was treated with radiation to the right shoulder and axillary masses for 12 days in December 2018. The treatment was initially intended to continue, but the decision was made to shorten his course considering his worsening prognosis and inability to pursue systemic chemotherapy. He was eventually moved to comfort care and expired shortly thereafter.

\section{Discussion}

Eccrine porocarcinoma (EPC) is an exceedingly rare cutaneous adnexal tumor with high potential for morbidity and mortality.(Nazemi et al., 2018) Although any body site can be affected, EPC typically presents on the head and neck.(Salih et al., 2017b; Riera-Leal et al., 2015; Robson et al., 2001) At the time of presentation, tumor size generally varies from $<1 \mathrm{~cm}$ to $10 \mathrm{~cm}$. (Robson et al., 2001) EPC cases have been reported to slowly arise from a preexisting benign eccrine poroma, however rapid development of de novo lesions is also well documented.(Robson et al., 2001)

Malignant tumor cells with nuclear atypia, hyperchromatic nuclei, foci of necrosis and frequent mitoses are characteristic features of EPC on histopathological examination.(Choi et al., 2011) Occasionally, cords and nests of polygonal tumor cells penetrating to adjacent dermis or extending into subcutaneous tissue have also been identified.(Choi et al., 2011) Epithelial cell abnormalities are not sufficient to make a diagnose of EPC according to Abenoza and Ackerman, as this may be apparent in benign eccrine poromas. The diagnosis of EPC is based on an invasive architectural pattern and the formation of cohesive basaloid epithelial cells.(Robson et al., 2001) Roaf et al. asserted EPC as seeming "benign" lesions on histological examination with locally aggressive behavior and further metastases.(Robson et al., 2001) Additionally, Shaw et al. contend two different classifications of EPC: an "infiltrative" type defined based on the nature of advancing tumor margin 


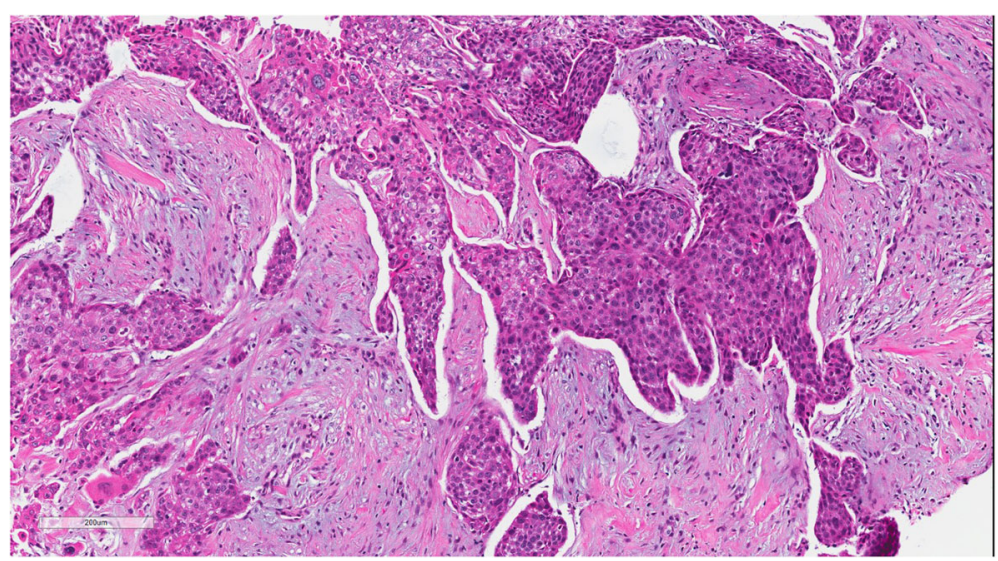

Fig. $2 \mathrm{H}$ \& E on high magnification (40x) showing tumor cells with anastomosing cords

irrespective of the degree of cytologic atypia; and the "cytologic" type with malignant cellular features and necrosis.(Robson et al., 2001) Because of synchronous epidermoid differentiation, diagnosis of EPC can be further supported by immunohistochemical staining for carcinoembryonic antigen (CEA), epithelial membrane antigen (EMA), and p53. (Robson et al., 2001; Parmar et al., 2016; Akalin et al., 2001) Positive staining for CEA and/or EMA usually accentuates ductal differentiation. (Robson et al., 2001; Parmar et al., 2016) Our case also showed infiltrative margins and positive CEA staining.

EPCs that are greater than $7 \mathrm{~mm}$ in thickness generally have more than 14 mitoses per high power field, or have lymphovascular invasion, and tend to carry a poor prognosis.(Robson et al., 2001; Parmar et al., 2016; Mahomed et al., 2008) However, generally tumor thickness is considered to be the main

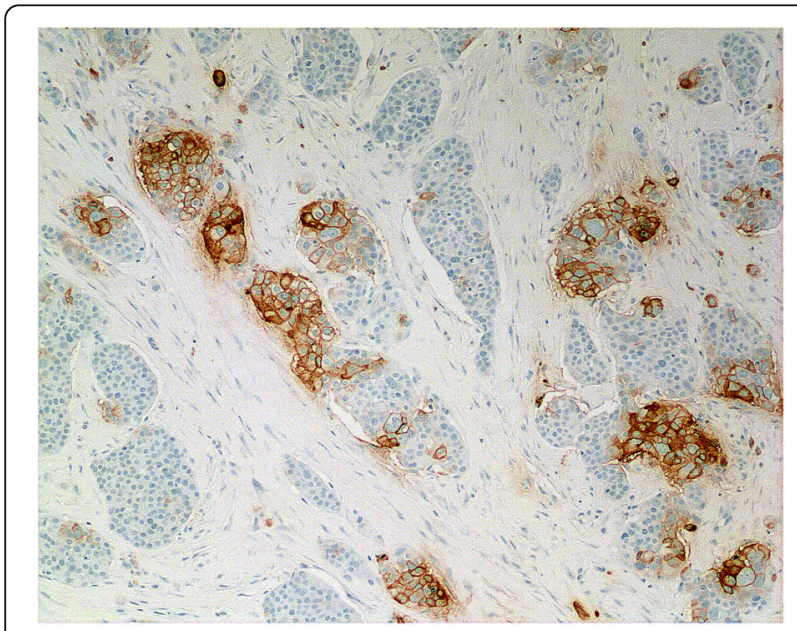

Fig. 3 Clinical image showing necrotic and fungating shoulder mass prognostic factor for EPC.(Robson et al., 2001; Parmar et al., 2016) Sentinel node biopsy has been proven to be advantageous tool for revealing metastasis to regional lymph nodes.(Robson et al., 2001; Parmar et al., 2016)

Mahomed et al reported five cases of porocarcinomas in patients with histories of immunocompromised conditions: two out of five cases were the acquired immune deficiency syndrome (AIDS) and the other three were recipients of renal transplants.(Salih et al., 2017b; Mahomed et al., 2008) Belin et al also investigated two patients (one for chronic lymphoid leukemia and the other for renal transplantation) with porocarcinoma who received immunosuppressing medications.(Salih et al., 2017b; Belin et al., 2011) Other authors also reported several of their patients who had similar histories of immunosuppressing treatment, and few others were

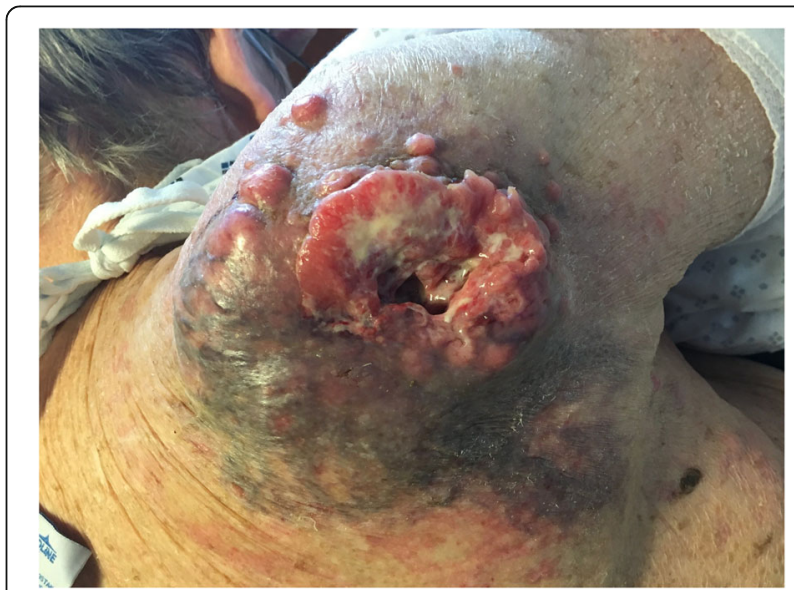

Fig. 4 Carcinoembryonic antigen (CEA) immunostain has a membranous pattern around a subset of tumor cells and highlights irregular ductal structures 


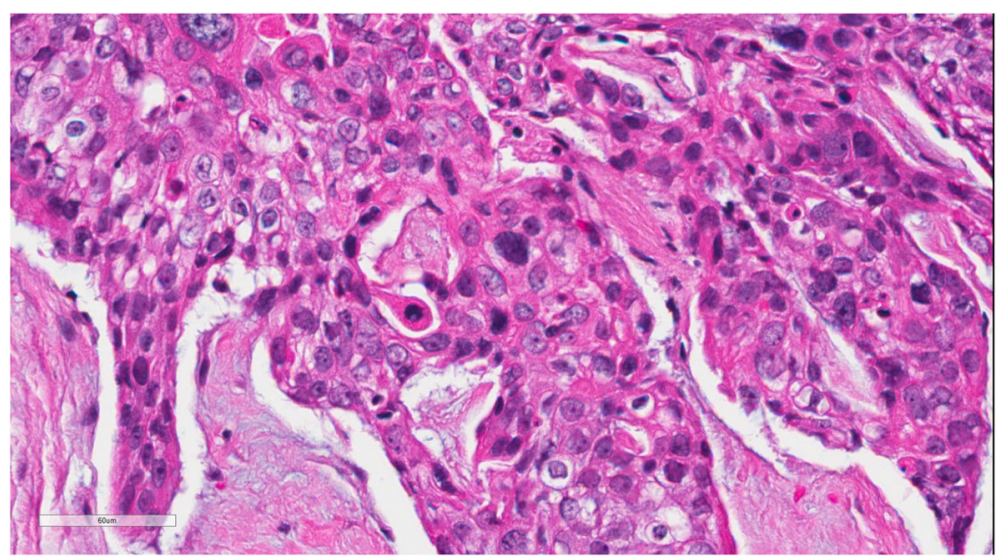

Fig. $5 \mathrm{H}$ \& E on high magnification (40x) showing malignant epithelial tumor cells forming ductal structures

immunocompromised due to underlying medical illnesses.(Salih et al., 2017b; Mahomed et al., 2008; Belin et al., 2011; Kim et al., 2005) Our case further supports the role of immunosuppression in the development of EPC given our patients' history of lung transplantation ten years before the diagnosis of EPC.

The presence of an infiltrating margin or marked cellular atypia should remind the pathologist to recommend reexcision and consideration of regional lymph node evaluation if there is doubt regarding the completeness of tumor removal. Surgery remains the principle management strategy for localized disease, with adjuvant chemoradiotherapy considered, especially if there is recurrence or metastasis.(Salih et al., 2017a; Salih et al., 2017b; Plunkett et al., 2001; Ramirez et al., 2012; Aaribi et al., 2013)

\section{Summary}

We are reporting an occurrence of metastatic eccrine porocarcinoma with an infiltrating margin on the back of an immunosuppressed patient. The presence of an infiltrating margin should alert the pathologist to recommend wider excision margins and regional lymph node dissection if there is uncertainty regarding completeness of excision. Radiotherapy and chemotherapy are necessary when presented with metastasis and recurrence. Due to the limited number of cases reported in the literature, it is very important to have a basic knowledge of this disease process as a differential diagnosis when dealing with such aggressive cutaneous lesions. Our patient's history of immunosuppression further supports a possible role for chronic immunosuppression in the carcinogenesis and metastasis of eccrine porocarcinomas. Further research may be useful

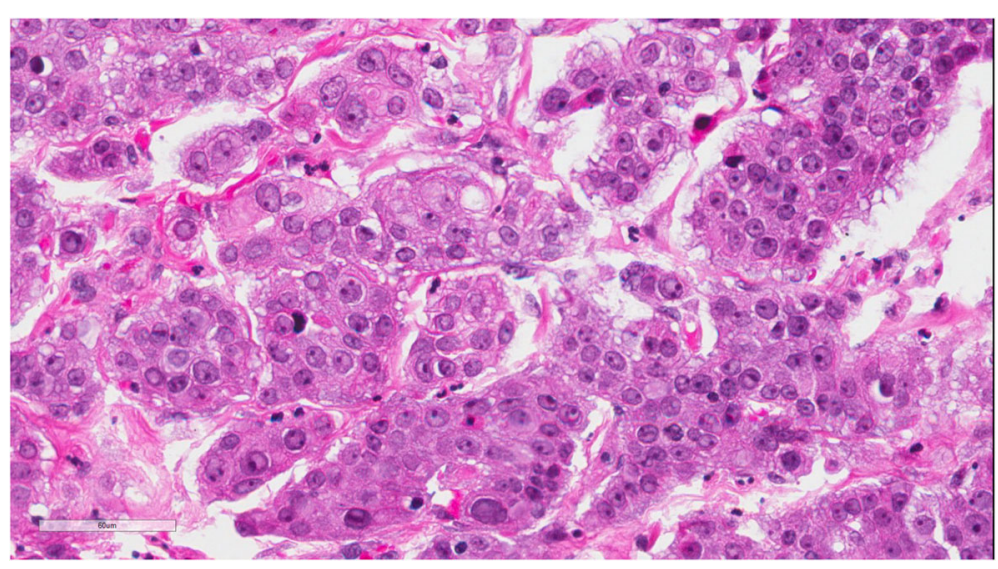

Fig. $6 \mathrm{H}$ \& E on high magnification (40x) showing pleomorphic tumor cells with enlarged, hyperchromatic nuclei and prominent nucleoli 
in exploring the possibility of an infectious etiology, as has been found to drive several malignancies in the immunocompromised patient populations.

\section{Abbreviations}

EPC: Eccrine porocarcinoma; CK: Cytokeratin; CEA: Carcinoembryonic Antigen; CT: Computed tomography; MRI: Magnetic Resonance Imaging; IV: Intravenous; EMA: Epithelial Membrane Antigen

\section{Acknowledgements}

Not Applicable.

\section{Authors' contributions}

MBM, AM, XX and DE edited and finalized the manuscript. DE performed the histological examination of the final resection. The authors read and approved the final manuscript. TS and MMihm provided the diagnosis on the initial biopsy with supporting immunohistochemical stains.

\section{Authors' information}

Not Applicable.

\section{Funding}

No funding.

\section{Availability of data and materials}

Not Applicable.

\section{Ethics approval and consent to participate}

Not Applicable (University of Pennsylvania research protocol).

\section{Consent for publication}

Appropriate consent was obtained for publication of the manuscript. (University of Pennsylvania research protocol).

\section{Competing interests}

The authors declare that they have no competing interests.

\section{Author details}

'Department of Pathology and Laboratory Medicine, Pennsylvania Hospital of the University of Pennsylvania Health System, Philadelphia, PA, USA. ${ }^{2}$ Department of Medicine, Division of Dermatology, University of Washington, Seattle, WA, USA. ${ }^{3}$ Dianon Pathology, Shelton, CT, USA. ${ }^{4}$ Department of Dermatology, Harvard Medical School and Mihm Cutaneous Pathology Consultative Service, Boston, MA, USA. ${ }^{5}$ Department of Pathology and Laboratory Medicine and Dermatology, Hospital of the University of Pennsylvania, Philadelphia, PA, USA.

Received: 6 April 2020 Accepted: 28 July 2020

Published online: 25 August 2020

\section{References}

Aaribi I, Mohtaram A, Ben Ameur El Youbi M, Kharmoum J, El Kabous M, Mrabti H et al (2013) Successful management of metastatic eccrine porocarcinoma. Case Rep Oncol Med 2013:282536. https://doi.org/10.1155/2013/282536

Akalin T, Sen S, Yücetürk A, Kandiloğlu G (2001) P53 protein expression in eccrine poroma and porocarcinoma. Am J Dermatopathol 23(5):402-406

Belin E, Ezzedine K, Stanislas S, Lalanne N, Beylot-Barry M, Taieb A et al (2011) Factors in the surgical management of primary eccrine porocarcinoma: prognostic histological factors can guide the surgical procedure. $\mathrm{Br} J$ Dermatol 165(5):985-989. https://doi.org/10.1111/j.1365-2133.2011.10486x

Choi C-M, Cho H-R, Lew B-L, Sim W-Y (2011) Eccrine Porocarcinoma presenting with unusual clinical manifestations: a case report and review of the literature. Ann Dermatol 23(Suppl 1):S79-S83. https://doi.org/10.5021/ad.2011. 23.S1.S79

Kim Y, Scolyer RA, Chia E-M, Steven D, Ghabrial R (2005) Eccrine porocarcinoma of the upper eyelid. Australas J Dermatol 46(4):278-281. https://doi.org/10. $1111 / j .1440-0960.2005 .00201 . x$

Mahomed F, Blok J, Grayson W (2008) The squamous variant of eccrine porocarcinoma: a clinicopathological study of 21 cases. J Clin Pathol 61(3): 361-365. https://doi.org/10.1136/jcp.2007.049213
Nazemi A, Higgins S, Swift R, In G, Miller K, Wysong A (2018) Eccrine Porocarcinoma: new insights and a systematic review of the literature. Dermatol Surg 44(10):1247-1261. https://doi.org/10.1097/DSS. 0000000000001566

Parmar N, Mohamed M, Elmoghrabi A, McCann M (2016) Eccrine Porocarcinoma presenting as an abdominal wall mass in a patient with ulcerative colitis-a rare case report. Int J Surg Case Rep 23:40-43. https://doi.org/10.1016/j.jscr. 2016.03.046

Plunkett TA, Hanby AM, Miles DW, Rubens RD (2001) Metastatic eccrine porocarcinoma: response to docetaxel (Taxotere) chemotherapy. Ann Oncol 12(3):411-414

Ramirez Y, Fellegara G, Bugiani M (2012) Eccrine porocarcinoma with carcinomatous lymphangitis in a patient with history of arsenic exposure: a case report. Int J Surg Pathol 20(5):515-518. https://doi.org/10.1177/ 1066896911428738

Riera-Leal L, Guevara-Gutiérrez E, Barrientos-García JG, Madrigal-Kasem R, BriseñoRodríguez G, Tlacuilo-Parra A (2015) Eccrine porocarcinoma: epidemiologic and histopathologic characteristics. Int J Dermatol 54(5):580-586. https://doi. org/10.1111/ijd.12714

Robson A, Greene J, Ansari N, Kim B, Seed PT, McKee PH, Calonje E (2001) Eccrine porocarcinoma (malignant eccrine poroma): a clinicopathologic study of 69 cases. Am J Surg Pathol 25(6):710-720

Salih AM, Kakamad FH, Baba HO, Salih RQ, Hawbash MR, Mohammed SH et al (2017b) Porocarcinoma; presentation and management, a meta-analysis of 453 cases. Ann Med Surg (Lond) 20:74-79. https://doi.org/10.1016/j.amsu. 2017.06.027

Salin AM, Kakamad FH, Essa RA, Rauf GM, S AM, H MS et al (2017a) Porocarcinoma: a systematic review of literature with a single case report. Int J Surg Case Rep 30:13-16. https://doi.org/10.1016/j.jscr.2016.10.051

\section{Publisher's Note}

Springer Nature remains neutral with regard to jurisdictional claims in published maps and institutional affiliations.
Ready to submit your research? Choose BMC and benefit from:

- fast, convenient online submission

- thorough peer review by experienced researchers in your field

- rapid publication on acceptance

- support for research data, including large and complex data types

- gold Open Access which fosters wider collaboration and increased citations

- maximum visibility for your research: over $100 \mathrm{M}$ website views per year

At BMC, research is always in progress.

Learn more biomedcentral.com/submissions 